\title{
Mass Spectrometry Study of Ammonia Formed During Plasma Nitrocarburizing and Nitriding Processes
}

\author{
Paola Egert ${ }^{a} *$, Heloisa Regina Turatti Silva ${ }^{a}$, Carlos Viana Speller ${ }^{b}$, Jayr de Amorim ${ }^{c}$, Allan Seeber ${ }^{d}$ \\ ${ }^{a}$ Unidade Acadêmica das Ciências da Produção, Construção e Agronegócio, Universidade do Sul de \\ Santa Catarina, 88137- 270, Palhoça, SC, Brasil \\ ${ }^{b}$ Departamento de Engenharia Mecânica, Laboratório de Materiais - LABMAT, Universidade Federal \\ de Santa Catarina, 88040-900, Florianópolis, SC, Brasil \\ 'Departamento de Física, Instituto Tecnológico de Aeronáutica-ITA, 12228-900, São José dos Campos, \\ SP, Brasil \\ ${ }^{d}$ Engenharia de Energias Renováveis e Meio Ambiente, Universidade Federal do Pampa, 96400-100, \\ Bagé, RS, Brasil
}

Received: February 20, 2018; Revised: May 16, 2018; Accepted: June 08, 2018

In this work, we used mass spectrometry to investigate ammonia $\left(\mathrm{NH}_{3}\right)$ formed during the nitrocarburizing and nitriding processes of $\alpha-\mathrm{Fe}$ sintered and low alloy steel by using d.c. glow discharges in different $\mathrm{N}_{2} / \mathrm{H}_{2} / \mathrm{CH}_{4}$ gas concentration mixtures. Experiments were conducted using two different configurations: one to collect and analyze species probed primarily in the bulk of the plasma, at a position distant from the heated sample; and the other to collect and analyze species very close to the reactive surface of the heated sample in such a way as to allow the analysis of lower concentration or residence time species, formed at the plasma/sample surface interface. Use of these configurations contributed to the investigation of the physical chemistry involved in the above plasma processes. An exchange the expected stoichiometry in ammonia formation in $\mathrm{N}_{2} / \mathrm{H}_{2} / \mathrm{CH}_{4}$ mixtures, with a shift towards higher nitrogen consumption, is observed and is interpreted an indication of nitrogen removal from the surface associated with ammonia and carbonitrides/nitrides formation. The present results point to the existence of a correlation between the nitrocarburizing and nitriding processes with respect to the formation of non-stoichiometric ammonia as a product.

Keywords: ammonia synthesis, nitrocarburizing, nitriding, plasma, glow discharge, mass spectrometry.

\section{Introduction}

Plasma nitrocarburizing and nitriding are thermochemical processes. In the former, nitrogen and carbon atoms diffuse into the surface of a ferrous substrate heated below the lower critical temperature, forming a compound layer and a subsurface diffusion layer, whereas in nitriding only nitrogen atoms are introduced into the subsurface matrix. These treatments change significantly the mechanical properties of the material surface, such as wear resistance and corrosion and micro hardness, without changing the performance characteristics of the material core.

Although considerable information is available, a complete understanding of the absorption mechanisms of carbon and nitrogen atoms presented in the literature for the plasma nitrocarburizing and nitriding process remains an open question. Nitrocarburizing and Nitriding are complex processes depending on many parameters. The plasma used for treatments is a very rich and reactive medium. A large number of chemical species and a considerable number of reactions continuously taking place within it and which involve different physic-chemical processes, such as ionization, neutralization, excitation, charge transfer, decomposition,

"e-mail: paola.egert.ortiz@gmail.com are to be considered in any attempt at modeling. The analysis of the chemical reactions of these species in the plasma atmosphere and with the surface of the material to be treated becomes rather difficult and leads to different mechanisms of atom absorption into the metal surface during the process. A good example in this respect is given by Sun and Bell ${ }^{1}$ in a modeling work on plasma nitriding of low alloy steels.

Nitrogen and carbon atoms are amongst the species efficiently formed in the plasma used for nitrocarburizing. These species can be very reactive and their chemistry leads to an improvement in the diffusion of atoms into the ferritic matrix, even at temperatures lower than those used in conventional treatments. In addition to their reactivity, the ion bombardment onto the substrate surface along with the fast neutrals is responsible for heating the substrate to the processing temperature.

From the different mechanisms proposed so far to explain plasma processes, such as nitriding, carburizing or nitrocarburizing, we can reasonably infer that nitrogen and carbon mass transfer during plasma treatment is the result of competition and accumulated effects of various reactions. In these, several intermediate species may be involved through gaseous and gas-surface reactions. During 
carburizing in plasma-enhanced processes in $\mathrm{H}_{2}$, for instance, it has been suggested ${ }^{2,3}$ that carbon radicals $\left(\mathrm{CH}_{\mathrm{x}}\right)$ and ions $\left(\mathrm{CH}_{\mathrm{x}}^{+}\right)$contribute to carbon transfer to the ferritic matrix following their adsorption and decomposition on the surface. In nitrocarburized samples, $\mathrm{Li}$ and Manory ${ }^{4}$ detected the presence of hydrogen, which they attributed to the presence of $\mathrm{CH}_{\mathrm{x}}(\mathrm{x}=1-3)$ species. The authors claim that in the initial nucleation stage, radicals of the type $\mathrm{CH}_{x}$ close to the surface will be bound to the surface by chemisorption to initially form the unstable intermetallic compound $\mathrm{FeNCH}_{x}$, and finally form stable carbonitrides $\varepsilon-\mathrm{Fe}_{2-3}(\mathrm{CN})_{1-\mathrm{x}}$ and $\gamma^{\prime}-\mathrm{Fe}_{4}(\mathrm{CN})_{1-\mathrm{x}}$. In an attempt to study the nitriding process in $\mathrm{N}_{2}-\mathrm{H}_{2}$ mixtures using mass spectrometry, Szabo and Wilhelmi ${ }^{5}$ detected mass/charge ratios to which they assigned $\mathrm{FeNH}_{2-3}$ species. They postulate that the interaction of these intermetallic compounds with the sample surface would form iron nitrides with greater stability that diffuse into the sample resulting in ammonia formation, which is finally released into the plasma.

In the present work, we restrict our efforts to the study of $\mathrm{NH}_{3}$, thus giving continuity to our previous investigation of the nitriding process. We previously carried out preliminary nitriding experiments ${ }^{6,7}$, in which the formation of ammonia was observed in the gas phase, consistent with the results obtained by $\mathrm{Szabo}^{5}$ for the nitriding process. Furthermore, a correlation was found between the ammonia profile and the surface Fe-nitride diffusion layer. In the present work, the investigation of ammonia formation was extended to the plasma nitrocarburizing process. As in the previous works, to satisfy our concern in the diagnosis of the nitrocarburizing and nitriding processes, mass spectrometry was used to investigate neutral species formed during the process in $\mathrm{N}_{2} /$ $\mathrm{H}_{2} / \mathrm{CH}_{4}$ gas mixtures.

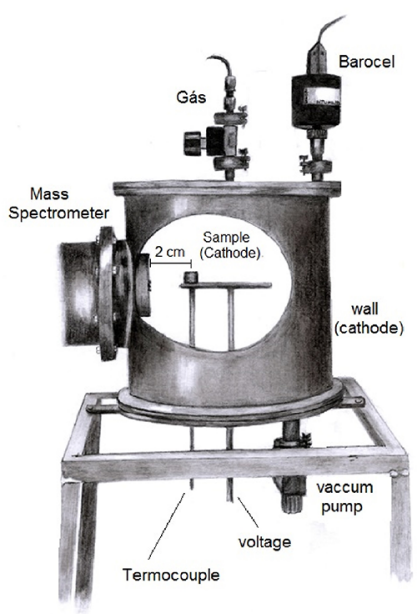

(a)

\section{Material and Methods}

\subsection{Reactor, vacuum system and general conditions}

The present experimental system is basically the same as the once conceived by Seeber ${ }^{8}$ in our laboratory, with some modifications. The nitrocarburizing and nitriding process were performed in a cylindrical plasma reactor (Figure 1) of AISI 304 stainless-steel (18-20 \% wt Cr; 8.0-10.5 \% wt Ni; other minority components, including $0.08 \max$ C, $2.0 \max \mathrm{Mn}$ and $1.0 \mathrm{max} \mathrm{Si}$ ), supplied with two transparent windows (not shown in the figure), normally used for visual observation of the discharge and for spectroscopic measurements, and a flange connection for a mass spectrometer.

The top and bottom steel plates were sealed to the body with O-rings and held connections for the gas inlet, vacuum manifold, electrodes and sensors (temperature and pressure). A valve in series with a two stage mechanical rotary pump was used to pump the reactor volume down to approximately $1 \mathrm{~Pa}\left(\sim 10^{(-2)}\right.$ Torr $)$ and maintain pressure inside at the desired values during the experiment. The cathode was constituted by the sample substrate to be treated and the anode by the walls of the reactor.

The nitrocarburizing and nitriding process were performed at a pressure and temperature of $400 \mathrm{~Pa}$ (3 Torr) and $550^{\circ} \mathrm{C}$, respectively. A membrane manometer was used to measure the pressure inside the reactor and the sample temperature was given by a thermocouple. $\mathrm{N}_{2}$ (purity $99.999 \%$ ), $\mathrm{H}_{2}$ (purity $99.999 \%$ ) and $\mathrm{CH}_{4}$ (purity 99.995\%) were dynamically mixed with varied mixing ratios. To control the introduction of gases, separated flowmeters were used. Moreover, the relation of pumping speed to gas flow (the total value of

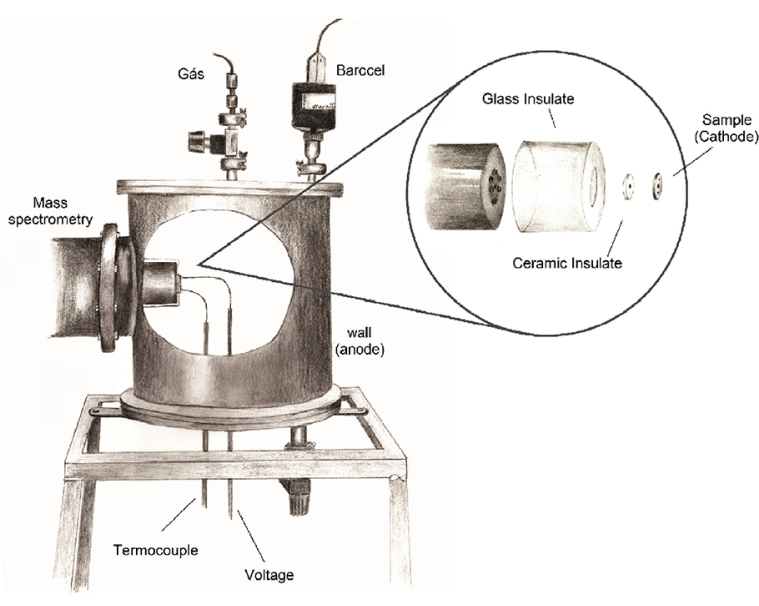

(b)

Figure 1. Schematic representation of the experimental set-up. (a) Bulk Configuration and (b) Surface Configuration 
which in this work was equal to $3.3 \mathrm{~cm}^{3} \cdot \mathrm{s}^{-1}$ ) was regulated to keep the intended pressure constant in the reactor.

Power transferred to the plasma was delivered by a square pulsed waveform d.c. power supply, with maximum voltage peak ranging from 400 to $700 \mathrm{~V}$ in steps of $100 \mathrm{~V}$, and a maximum current of $5 \mathrm{~A}$. The negative voltage output was connected to the cathode (sample) and the positive one (reactor walls) was grounded. The time of the pulse switched on could be varied from 10 to $240 \mu$ s with a total time on/ off of $240 \mu \mathrm{s}$, thus allowing the adjustment of the power transferred to the plasma. After the adjustment, the conditions remained constant for all the experiments in this work.

\subsection{Diagnostics and sample configurations}

A scanning electron microscope (SEM) (Philips XL30) with energy dispersive $\mathrm{X}$-ray spectroscopy (EDX) was available for morphological analysis in the samples treated. The SEM micrographs were used for the microstructure evaluation as well as to measure the thickness of the carbonitride and nitride layers formed.

Infrared (IR) spectroscopy (SHIMADZU IR-408) coupled to a condensation device was performed to identify some of the species, like amines. The monitoring of most of the neutral chemical species formed during the process was carried out using a mass spectrometer (MS) (VG SXP Elite $600)$ coupled to the plasma chamber through a small conical orifice $(\varnothing=100 \mu \mathrm{m})$, and capable of analyzing mass to charge number ratios $(\mathrm{m} / \mathrm{z})$ from 1 to $600 \mathrm{u}$ (unified atomic mass unit). Neutral species collected from the plasma reactor enters the MS, where they are ionized by electron impact, filtered and detected. The electron energy in the source may be varied to produce maximum ionization efficiency, which is typically done with $70 \mathrm{eV}$ electrons, or used as a tool to discriminate possible ionic fragments presenting mass coincidence (different species for the identified mass) or when assigning the respective ion to the corresponding mother molecule (different mother molecules for the identified ion species). In the present experimental conditions, the molecular ion $\mathrm{NH}_{3}^{+}$ presented the most suitable conditions for the monitoring of the neutral species $\mathrm{NH}_{3}$. The ionization energy to produce $\mathrm{NH}_{3}{ }^{+}$by electron impact on $\mathrm{NH}_{3}$ is equal to approximately $10 \mathrm{eV}^{9}$ and the electron energy in the ionization chamber was fixed at $17.0 \mathrm{eV}$. This value was chosen to allow the detection of $\mathrm{NH}_{3}$ while discriminating the contribution from $\mathrm{OH}^{+}$ions $\left(\mathrm{OH}^{+}\right.$and $\mathrm{NH}_{3}^{+}$have both $\left.\mathrm{m} / \mathrm{z}=17 \mathrm{u}\right)$, formed from the dissociative ionization of the unavoidable residual water with a corresponding appearance energy of about $18.0 \mathrm{eV}^{9}$, and so higher than the electron energy used in our experiment. Although the observed signal of $\mathrm{NH}_{3}{ }^{+}$was already considerably weak in the normal conditions of our experiment, and significantly lowered under this rigorous condition of the electron energy, due to the lowering of the ionization cross section ${ }^{9,10}$, its identification was unambiguous.
An intermediary pumped chamber coupled between the quadrupole and the plasma chamber enabled the sampling of gases at the desired pressure ( $400 \mathrm{~Pa} \cong 3$ Torr), which lie well below the upper limit of the instrument (normally above $1300 \mathrm{~Pa} \cong 10$ Torr). The cylindrical head of the MS, located inside the plasma chamber, was electrically insulated from the MS body by a ceramic ring, which was adequately protected against the formation of plasma arcs by a borosilicate glass tube. The vacuum in the two MS chambers was generated by two pumping systems, respectively, each consisting of a turbomolecular and a two-stage mechanical rotary pump in conjunction with a gate valve. Pressures in the MS chambers were measured with penning manometers.

Bulk configuration - In the first, named bulk configuration, a cylindrical sample of $0.8 \mathrm{~cm}$ in diameter and $0.5 \mathrm{~cm}$ thickness of pure iron $(\alpha-\mathrm{Fe})$ was placed on a vertical holder, approximately $2 \mathrm{~cm}$ from the MS gas collecting orifice, as shown in Figure 1a. In this mode, the species collected are primarily those extracted from the bulk of the plasma.

Surface configuration - In the second, named surface configuration, the sample to be treated had a hole in its center and was coaxially juxtaposed directly on the MS flange containing the gas collecting orifice (Figure 1b). In this case, when compared with the bulk configuration, the collection of the species formed in the cathode surface glow area is expected to be enhanced. The sample was thermally insulated from the metallic MS flange by very thin ceramic flat rings, thus minimizing undesirable heat loss from the sample (heated cathode) to the MS body. As plasma arcs were also observed sometimes on the edges of the screws holding the orifice flange, they also were protected by small ceramic tubes. Disk samples of $2.0 \mathrm{~cm}$ in diameter and 0.3 $\mathrm{cm}$ thickness with a conical hole of $0.05 \mathrm{~cm}$ in diameter at their center, of low alloy steel, were used in the surface configuration experiments.

\subsection{General procedure}

In the nitrocarburizing experiments, the following procedure was adopted before each run of the experiment. First, the reactor volume was evacuated for four hours, followed by wall and sample cleaning with a hydrogen discharge for 30 minutes. The temperature of the sample reached $300^{\circ} \mathrm{C}$ during the cleaning. After preparation and calibration of the initial gas mixture, the discharge was switched on and the discharge current was slowly increased until the desired temperature $\left(550^{\circ} \mathrm{C}\right)$ for the sample was reached and stabilized. Approximately 40-50 minutes were required for the sample heating. Measurements of the dependence of mass peak intensities of the chemical species with the gas mixture composition were then initiated. Each complete run to follow the evolution of peaks lasted approximately 40-50 minutes. This included around 3-4 minutes to set up each mixture condition needed to change the gas-mixing ratio and make the corresponding measurement. Each point in 
the figures represented a specific gas mixture composition. To ensure that the results were reproducible, each complete experiment was performed three times. However, each run corresponded to a new sample.

Because the total pressure was kept constant in a mixture containing three different gases, $\mathrm{N}_{2} / \mathrm{H}_{2} / \mathrm{CH}_{4}$, whenever the mixing ratio of the gas of interest was changed, the pressure balance of one of the two other gases was necessarily performed with one of them fixed at a constant mixing ratio. The choice depended on the interest. As a general rule, when $\mathrm{H}_{2}$ was used as the variable gas of interest, the mixing ratio of $\mathrm{CH}_{4}$ was fixed at $3 \% \mathrm{vol}$ or $0 \% \mathrm{vol}$, for nitrocarburinzing and nitriding, respectivamente, and $\mathrm{N}_{2}$ was used as balance gas; for the $\mathrm{CH}_{4}$ dependence study, $\mathrm{N}_{2}$ pressure was fixed at $80 \%$ vol and $\mathrm{H}_{2}$ pressure was varied for balance.

Uncertainty of mass peak intensity measurements was estimated to within a maximum of $10 \%$. Because each experiment required a complete preparation procedure (reactor opening, sample replacement, chemical cleaning, pumping down, gas mixture preparation, plasma cleaning), it was sometimes difficult to reproduce the same conditions inside the reactor with desirable accuracy and, consequently, the absolute intensities were not always repetitive enough to allow direct comparison between different spectra (different experiments). To facilitate a comparison between different spectra, the data in most figures were normalized (unless specified otherwise) to the highest peak intensity obtained in the set of points for each corresponding figure. This procedure was useful when comparing plot profiles for different conditions (plasma process, sample material, gas mixing ratio).

Basically, the same procedure was followed in the nitriding experiments, albeit remembering that in this case the mixtures used did not contain $\mathrm{CH}_{4}\left(0 \%\right.$ vol CH $\left.\mathrm{CH}_{4}\right)$, i.e, $\mathrm{N}_{2}-\mathrm{H}_{2}$.

\section{Results and Discussion}

During the nitrocarburizing and nitriding plasma process using $\mathrm{N}_{2} / \mathrm{H}_{2} / \mathrm{CH}_{4}$ and $\mathrm{N}_{2} / \mathrm{H}_{2}$ gas mixtures, respectively, we have the formation of a number of chemical species that can be produced, not only in the gas phase but also at the substrate surface and on the reactor walls. As expected in this work, in addition to the chemical species of the introduced gases we detected and identified other species, such as $\mathrm{NH}_{3}, \mathrm{HCN}$, $\mathrm{C}_{3} \mathrm{H}_{8}, \mathrm{C}_{4} \mathrm{H}_{10}$, and $\mathrm{CH}_{3} \mathrm{NH}_{2}$, derived from chemical reactions occurring in the reactor. Except for $\mathrm{CH}_{3} \mathrm{NH}_{2}$ (methylamine, detected by IR spectroscopy), all these species seem to be commonly observed in electrical discharges in $\mathrm{N}_{2} / \mathrm{CH}_{4} / \mathrm{H}_{2}$ gas mixtures at low pressures ${ }^{11,12}$. Higher order hydrocarbon molecules, amines or cyanides were absent or very scarce. Nevertheless, except for $\mathrm{NH}_{3}$ and $\mathrm{HCN}$, the complexity of the obtained spectra and the feeble intensities found for most of the measured mass peaks at $17 \mathrm{eV}$ electron energy made it difficult to investigate the identified molecules, yielding unreliable results when the mixing ratio of the gas mixture was changed.

\subsection{Nitrocarburizing}

\subsubsection{Dependence of $\mathrm{NH}_{3}$ on $\mathrm{H}_{2}$}

Figures 2 and 3 show the evolution of the ammonia ion peak $\left(\mathrm{NH}_{3}^{+}\right)$obtained for the two configurations during the increase of the hydrogen mixing ratio in the $\mathrm{N}_{2} / \mathrm{H}_{2} / \mathrm{CH}_{4}$ mixture. The amount of $\mathrm{CH}_{4}$ in the mixture was kept constant, equal to $3 \% \mathrm{vol}$, and the fraction of hydrogen was increased from zero to the maximum value allowed in the gas mixture, when $\mathrm{N}_{2}$ decreased to $0 \%$ vol.

As will be seen below, the results for $\mathrm{NH}_{3}$ were differed significantly from one configuration to the other. A comparison of the results obtained with the two configuration modes allowed us to distinguish two groups of the same chemical species, one that was associated with the plasma bulk and another associated with the substrate surface, suggesting that the heated sample surface also influences and plays a role in the formation of ammonia.

\section{Bulk configuration}

When the bulk configuration was used with an initially untreated sample, the dependence of the $\mathrm{NH}_{3}$ intensity on the $\mathrm{H}_{2}$ volume fraction in the mixture showed a relatively rapid increase up to around $20-30 \%$ vol $\mathrm{H}_{2}$, followed by a broad section exhibiting a slow increase between approximately $20-30$ and $75-80 \% \mathrm{vol}_{2}$, finally decreasing until $100 \%$ vol $\mathrm{H}_{2}$ was achieved (Figure 2). The dispersion of the data in Fig. 2 is small and a polynomial fit indicates a maximum trend value of approximately 70-80\% vol $\mathrm{H}_{2}$. According to the literature ${ }^{13-16}$ on the heterogeneous ammonia synthesis in plasma-chemical conversions containing $\mathrm{N}_{2}$ $\mathrm{H}_{2}$ mixtures, different surfaces, including glass, iron and steel, act as catalysts for ammonia formation, in a process that basically involves the formation of $\mathrm{N}, \mathrm{H}, \mathrm{NH}, \mathrm{NH}_{2}$ and the catalyst surface. The balance of reaction equations gives $\mathrm{N}_{2}+3 \mathrm{H}_{2} \rightarrow 2 \mathrm{NH}_{3}$ with an expected stoichiometry

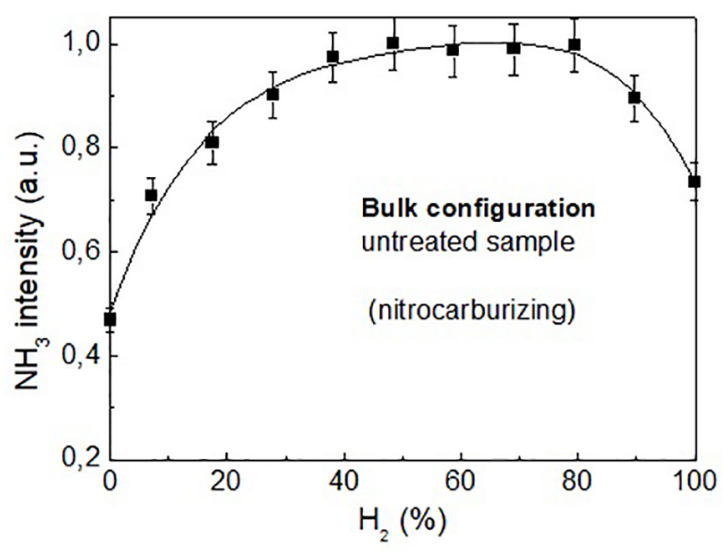

Figure 2. Evolution of the ammonia ion peak $\left(\mathrm{NH}_{3}+\right)$ obtained for the bulk configuration 
$\mathrm{N}_{2}: \mathrm{H}_{2}=1: 3\left(25 \% \mathrm{~N}_{2}: 75 \% \mathrm{H}_{2}\right)$ for $\mathrm{NH}_{3}$ formation through reactions on the walls ${ }^{17-19}$. Previous results from different authors, in different types of electrical discharges in $\mathrm{N}_{2}-\mathrm{H}_{2}$ mixtures yield the same stoichiometry, with slightly different profiles depending on the discharge type (e.g. Eremin et a $1^{15}$ in barrier discharge, Amorim et al. ${ }^{17}$ in dc glow discharge, Uyama et al. ${ }^{18}$ in microwave plasma, or Bai et al ${ }^{19}$ in strong electric field discharge at ambient pressure). However, as shown in Fig. 2, the observed dependence of $\mathrm{NH}_{3}$ on the $\mathrm{H}_{2}$ fraction in our methane containing mixture also displays a maximum of around $75 \%$ vol $\mathrm{H}_{2}$, the stoichiometric value. Moreover, the profile derived from the experimental results from Amorim $^{17}$, also in a de glow discharge for nitriding, and reported along with the fit of calculations ${ }^{11}$, compares reasonably well with our plot in Figure 2.

However, we see that the first point in Fig. 2, for $0 \%$ vol $\mathrm{H}_{2}$, departed significantly from zero. This occurred with all the data related to the $\mathrm{NH}_{3}$ vs. $\mathrm{H}_{2}$ measurements throughout this work, particularly for low $\mathrm{H}_{2}$ fraction, suggesting that another source of hydrogen may be involved in the measurements. It will be discussed in the $\mathrm{CH}_{4}$ dependence section that in the discharge hydrogen can be easily formed by different reactions of electron impact on $\mathrm{CH}_{4}$ and by bimolecular reactions in $\mathrm{N}_{2}-\mathrm{CH}_{4}$ mixtures, and that this is likely to be responsible for additional ammonia formation. This means that for low fractions of introduced hydrogen, and even for $0 \%$ vol hydrogen in the mixture, although to a lesser extent, we have to consider its contribution to the formation of ammonia. Furthermore, as remarked by Quandt ${ }^{20}$, after applying hydrogen plasma cleaning in this reactor, adsorbed $\mathrm{H}_{2}$ desorbs from the walls of the reactor and contributes to ammonia formation at the beginning of the nitriding process. In her measurements, a minimum of approximately $30 \mathrm{~min}$ were necessary until the $\mathrm{H}_{2}$ level decreased significantly before starting the measurements on nitriding.

Effects of the walls on conversion to ammonia related to the duration of the hydrogen plasma cleaning prior to the $\mathrm{N}_{2}-\mathrm{H}_{2}$ discharges are discussed by Touvelle et al. ${ }^{14}$. However, as will be shown, the results obtained regarding the surface configuration suggest the existence of a partial overlap of peaks in the bulk plot of Figure 2, indicating that a second reaction path regarding the formation of $\mathrm{NH}_{3}$ and possibly involving a higher consumption of nitrogen (lower $\mathrm{H}_{2}$ fraction in the figure) might be present. As we will see below, the use of the surface configuration yielded valuable results in support of this assumption.

\section{$\underline{\text { Surface configuration }}$}

Untreated sample - The same measurements made using the bulk configuration were repeated with the surface configuration under the same conditions. As shown in Figure 3, when the chemical species were collected directly through the cathode orifice, i.e., very close to the cathode surface chemistry region, the corresponding curve showed a unique and sharper maximum approximately between 20 and $25 \%$ vol $\mathrm{H}_{2}$ ( or $80-75 \%$ vol $\mathrm{N}_{2}$ ). No peak corresponding to the expected stoichiometry $\mathrm{N}_{2}: \mathrm{H}_{2}=1: 3$ was discerned while using the surface configuration. The broad central section of the profile observed when the bulk configuration was used was no longer seen and ammonia formation at a much lower hydrogen concentration now clearly predominated over the expected one corresponding to the known stoichiometry $\mathrm{N}_{2}: \mathrm{H}_{2}=1: 3$, i.e., resulting in a shift to much higher nitrogen consumption, with a corresponding volume ratio of $\mathrm{N}_{2}: \mathrm{H}_{2} \approx 3: 1$. This shift was observed whenever the surface configuration was used with an untreated sample and was attributed to the heated cathodic surface. A departure from $\mathrm{N}_{2}: \mathrm{H}_{2}$ stoichiometry for ammonia synthesis in $\mathrm{N}_{2}-\mathrm{H}_{2}$ mixtures was reported by Eremim ${ }^{15}\left(\mathrm{~N}_{2}: \mathrm{H}_{2}=2: 3\right)$ in an experiment with palladized Pd wires wound over the inner electrode of a $500 \mathrm{~Hz}$ wall-glass ozonizer. A tentative explanation was given on the basis of $\mathrm{N}_{2}^{+}$ions being discharged on the surface to produce $\mathrm{N}$ atoms, although the reason for the observed shift was not investigated.

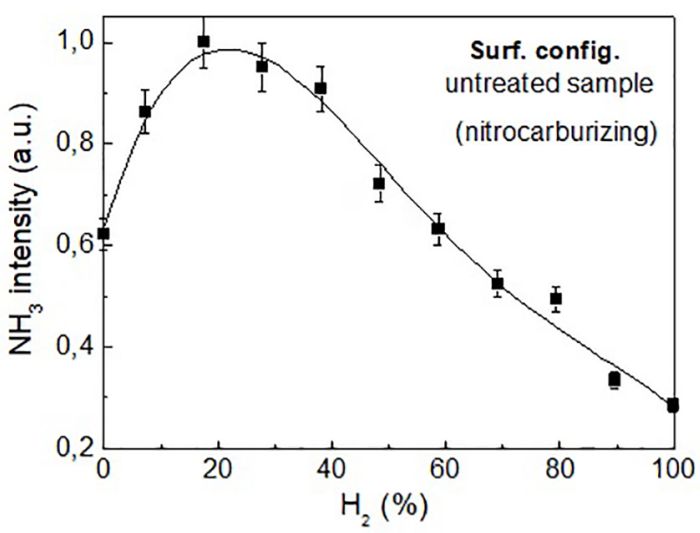

Figure 3. Evolution of the ammonia ion peak $\left(\mathrm{NH}_{3}+\right)$ obtained for the surface configuration

Pretreated sample - In an attempt to verify how the carbonitride layer formed during the nitrocarburizing process affected the measured ammonia profile, the same experiment

was repeated using a pretreated sample. The results are shown in Fig. 4.

When instead of an untreated sample one pretreated for two hours was used, a broad and irregular distribution was obtained. It may correspond two peaks presence. One corresponds to the $\mathrm{H}_{2}$ mixing ratio equal to approximately $20-25 \%$, roughly the same value already obtained with the surface configuration for the untreated sample. The other was formed at approximately $70-80 \%$, the same mixing ratio corresponding to the stoichiometric maximum observed with the bulk configuration (Figure 2) also by using the untreated sample. Figure 4 suggests that when the surface of the sample is pretreated, stoichiometric $\mathrm{NH}_{3}$ formation in the range of $70-80 \% \mathrm{vol} \mathrm{H}_{2}$ is favored. Apparently, unlike what was 


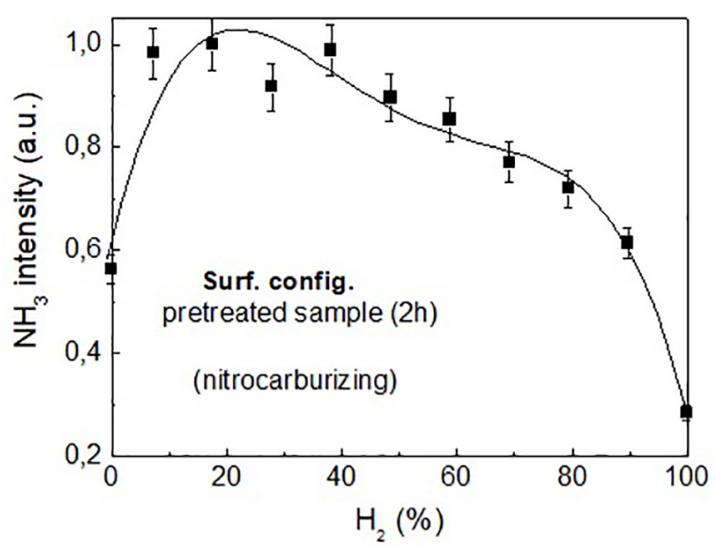

Figure 4. Evolution of the ammonia ion peak $\left(\mathrm{NH}_{3}+\right)$ obtained for the surface configuration using a pretreated sample

observed in the untreated sample case, the modified surface tends to inhibit in part the synthesis of non-stoichiometric ammonia. Consequently, its intensity is reduced. Accordingly, and because in principle the synthesis of the stoichiometric ammonia (around $75 \%$ vol $\mathrm{H}_{2}$ ) should not be affected by this to an important degree, both synthesis processes now yielded comparable intensities for the configuration used. Indeed we observed that the absolute intensity of $\mathrm{NH}_{3}$ at $75 \% \mathrm{vol} \mathrm{H}_{2}$ remained roughly the same (to within $20 \%$ ) as that observed in the bulk configuration, as should be expected for the ammonia synthesized on the walls. Actually, given the relatively small ratio between the sample (nonstoichiometric related) and the reactor wall (stoichiometric related) surfaces, the use of one or another configuration should not significantly affect the yield of the stoichiometric synthesis process. Nevertheless, it should be remembered that the present situation is physically different from that of the bulk configuration, where the cathode is far from the collecting orifice. Ultimately, the important difference lies in the fact that in the surface configuration the signal of the non-stoichiometric ammonia is enhanced, owing to the fact that this species is collected very close to the source that generates it, in practice even before it enters and effectively mixes itself into the plasma bulk space. This enhancement, together with the fact that the aforementioned inhibition is supposed to be partial for the sample pretreated for two hours, is probably the reason why Figure 4 still displays a reasonable yield of non-stoichiometric ammonia compared with the stoichiometric one while using a pretreated sample. As will be seen, the same behavior described for the pretreated sample in the nitrocarburizing process was also observed for the nitriding results (see Fig. 8-10, paragraph 3.2).

\subsubsection{Dependence of $\left(\mathrm{NH}_{3}, \mathrm{H}_{2}\right.$ and $\left.\mathrm{HCN}\right)$ on $\mathrm{CH}_{4}$}

The dependence of the formed ammonia was investigated as a function of the methane mixing ratio in the $\mathrm{N}_{2} / \mathrm{H}_{2} / \mathrm{CH}_{4}$ mixture, under constant total pressure, as defined previously. Furthermore, the same experiment, but with no addition of hydrogen to the mixture $\left(\mathrm{N}_{2}-\mathrm{CH}_{4}\right.$ discharge), was conducted to verify whether hydrogen generated from methane could be partially responsible for the detected ammonia. Finally, the dependence of $\mathrm{HCN}$ on $\mathrm{CH}_{4}$ was also verified with both configurations and, unlike the $\mathrm{NH}_{3}$ species, no difference was observed in this case.

i. $\mathrm{NH}_{3}$ vs. $\mathrm{CH}_{4}$

The results for the two configurations are shown in Fig. 5. The balance gas $\left(\mathrm{H}_{2}\right)$ fraction in the mixture decreases as that of $\mathrm{CH}_{4}$ increases. The fraction of $\mathrm{N}_{2}$ is a constant number $(80 \%)$ and the intensity of $\mathrm{NH}_{3}$ is plotted versus $\left[\mathrm{CH}_{4}\right] /\left(\left[\mathrm{CH}_{4}\right]+\left[\mathrm{H}_{2}\right]\right)$, in \%.

Once again, depending on the configuration used, the results for the ammonia formation reveal a different behavior.

In the bulk configuration, a constant region extends from zero to around $1.5-2.0 \% \mathrm{vol} \mathrm{CH}_{4}$, followed by a continuous increase up to $4 \%$. Unlike these results, when using the surface configuration an intermediary plateau is observed within approximately 1.5 and $2.5 \%$ vol $\mathrm{CH}_{4}$, between the initial and the end ascending parts of the curve. Except for the already observed distinct behavior of $\mathrm{NH}_{3}$ when using one or another configuration, no conclusion could be clearly inferred from these results.

ii. $\mathrm{H}_{2}$ vs. $\mathrm{CH}_{4}$ and $\mathrm{NH}_{3}$ vs. $\mathrm{CH}_{4}$

Hydrogen can easily be formed by several dissociative ionization and dissociation reactions in methane by electron impact in the discharge, as well as by reactions with active nitrogen ${ }^{12}$. To confirm whether hydrogen from methane could be partially responsible for the detected ammonia, the same experiment, but with no addition of hydrogen to the mixture (pure $\mathrm{N}_{2}-\mathrm{CH}_{4}$ discharge), was conducted in the surface configuration. $\mathrm{H}_{2}$ vs. $\mathrm{CH}_{4}$ and $\mathrm{NH}_{3}$ vs. $\mathrm{CH}_{4}$ were measured in a mixture of $\mathrm{N}_{2}$ with variable $\mathrm{CH}_{4}(0-4 \%$ vol $)$. The results are shown in Fig. 6a and 6b, respectively.

Except for the beginning, close to the axis origin, where we observe a constant intensity value of up to approximately $0.3 \%$ vol $\mathrm{CH}_{4}$, hydrogen increases linearly with $\mathrm{CH}_{4}$ up to the maximum content (i.e. $4 \%$ vol $\mathrm{CH}_{4}$ ). Accordingly, as expected, $\mathrm{NH}_{3}$ is also formed, though with a plateau less clear than in the preceding measurements of ammonia (Fig. 5b), as shown in Figure 6b. This shows, albeit to a lesser extent, that the contribution of hydrogen formed in the discharge should also be taken into account in the ammonia formation in the discharge, even when hydrogen is not introduced (pure $\mathrm{N}_{2}-\mathrm{CH}_{4}$ discharge). Moreover, Bai et al. ${ }^{21}$ reported the noncatalytic synthesis of ammonia using $\mathrm{N}_{2}-\mathrm{CH}_{4}$ plasmas based on a micro-gap discharge, with an average electron energy of $10 \mathrm{eV}$. A comparison of conditions in both discharges suggests that some ammonia synthesis is also possible in the present discharge.

iii. $\mathrm{HCN}$ vs. $\mathrm{CH}_{4}$ 


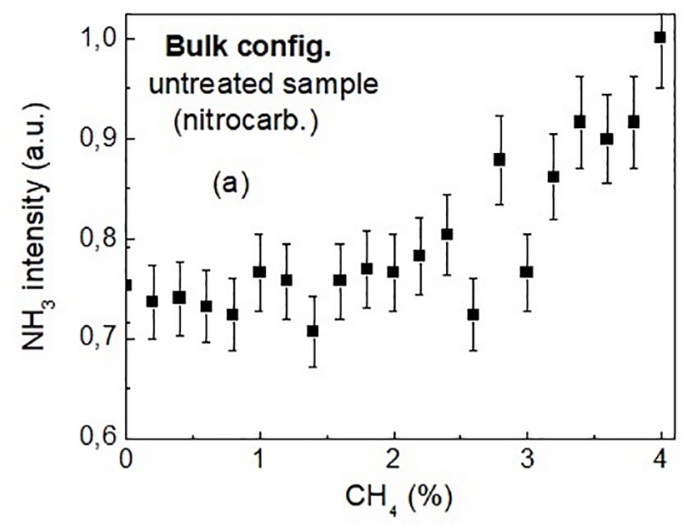

(a)

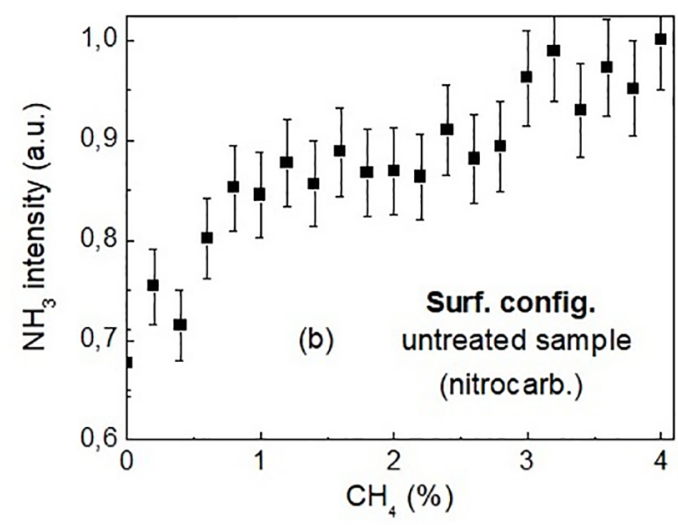

(b)

Figure 5. Evolution of the ammonia ion peak $\left(\mathrm{NH}_{3}^{+}\right)$obtained as a function of the methane mixing ratio in the $\mathrm{N}_{2} / \mathrm{H}_{2} / \mathrm{CH}_{4}$ mixture (a) Bulk configuration. and (b) Surface configuration

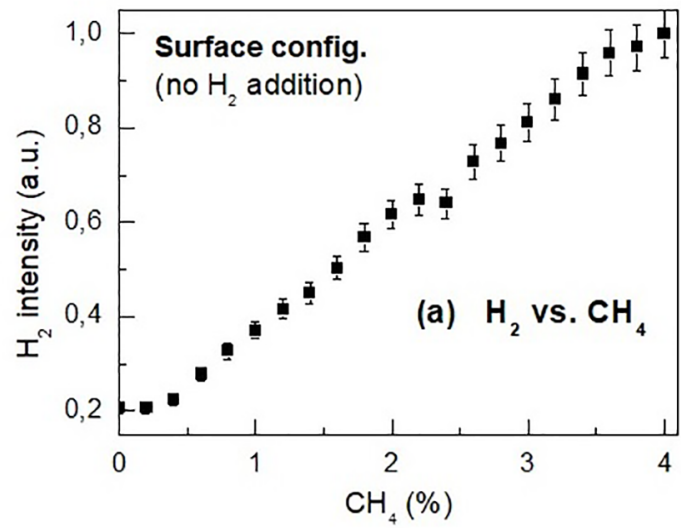

(a)

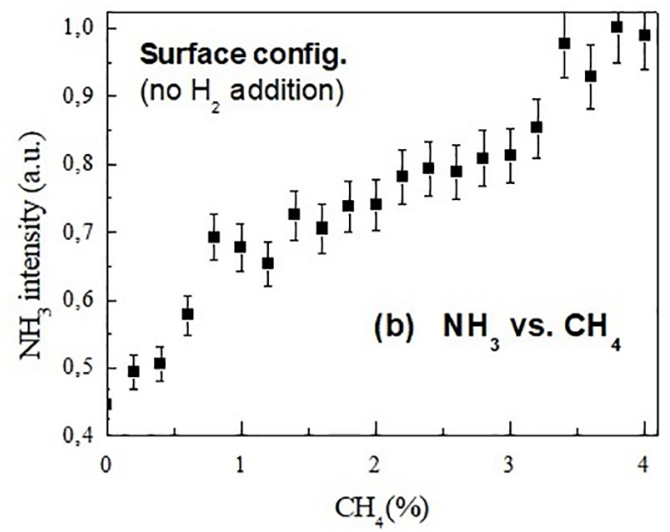

(b)

Figure 6. (a) Evolution of the hydrogen ion peak $\left(\mathrm{H}_{2}^{+}\right)$obtained as a function of the methane mixing ratio in the $\mathrm{N}_{2} / \mathrm{CH}_{4}$ mixture. and (b) Evolution of the ammonia ion peak $\left(\mathrm{NH}_{3}{ }^{+}\right)$obtained as a function of the methane mixing ratio in the $\mathrm{N}_{2} / \mathrm{CH}_{4}$ mixture

$\mathrm{HCN}$ is formed by fast reactions in a glow discharge containing $\mathrm{N}_{2}$ and $\mathrm{CH}_{4}{ }^{12}$ and was the most easily detected species in our mass spectra. The presence of $\mathrm{HCN}$ together with $\mathrm{CH}_{3} \mathrm{NH}_{2}$, deposited on the walls, was also confirmed by IR spectrophotometry* Its dependence on $\mathrm{CH}_{4}$ was also investigated and the results are presented in Fig. 7.

They are quite similar for both configurations, and no significant influence of the cathodic region is observed. This lends support to the claim that the distinct behavior observed between the results when using the two configurations is not applicable to all species detected and that in the present conditions it is believably a feature of the observed ammonia.

\subsection{Nitriding}

Similar and very plausibe results related to the present nitrocarburizing ones were obtained when investigating the nitriding of untreated sample of steel in the surface configuration, and pretreated sample of pure iron in bulk configuration. The results from the nitriding work of Szabo and Whilhelmi ${ }^{5}$ in steel will also be compared.

\subsubsection{Nitriding: surface configuration - untreated sample of steel}

Using basically the same experimental system as described above, nitriding experiments with $\alpha$-Fe were conducted ${ }^{7,22}$ using the surface configuration and untreated samples, under the same conditions used in the nitrocarburizing process. As in the case of the nitrocarburizing study with as untreated sample, when using the surface configuration a well-defined

\footnotetext{
"According to Pintassilgo et al..$^{12}$, $\mathrm{HCN}$ is easily deposited on the walls Furthermore, three-body reactions involving the walls as third-body can convert $\mathrm{HCN}$ into $\mathrm{H}_{2} \mathrm{CN}$.
} 


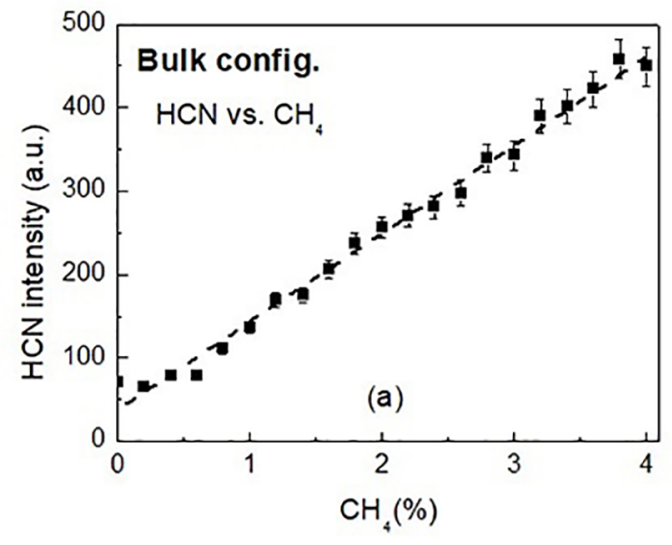

(a)

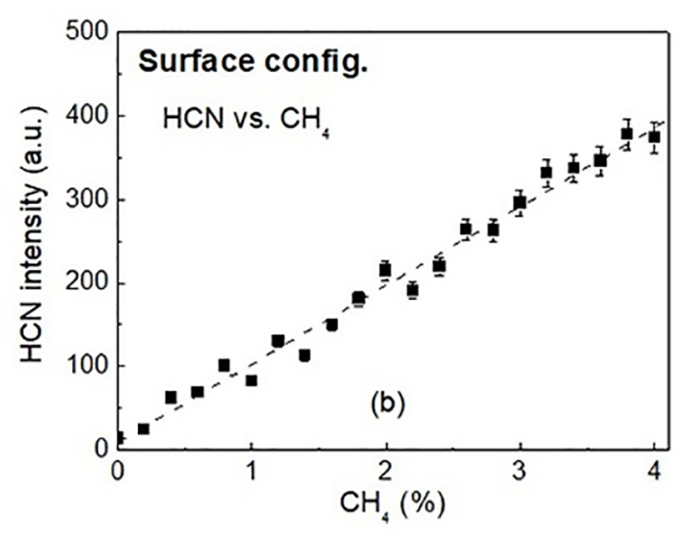

(b)

Figure 7. Evolution of the $\mathrm{HCN}$ (ion peak $\left(\mathrm{HCN}^{+}\right.$) obtained as a function of the methane mixing ratio in the $\mathrm{N}_{2} / \mathrm{H}_{2} / \mathrm{CH}_{4}$ mixture (a) Bulk configuration. and (b) Surface configuration

peak with a maximum value of around $20-30 \% \mathrm{vol} \mathrm{H}_{2}$ was observed in the $\mathrm{NH}_{3}$ investigation. The two curves show very similar profiles and compare very well with one another in the normalized mode, showing the same maximum value (Figure 8).

In other words, concerning the $\mathrm{NH}_{3}$ vs. $\mathrm{H}_{2}$ dependence, no noticeable difference was discerned between the results in the nitrocarburizing or nitriding of $\alpha-\mathrm{Fe}$, in $\mathrm{N}_{2}-\mathrm{H}_{2}-\mathrm{CH}_{4}$ and $\mathrm{N}_{2}-\mathrm{H}_{2}$ mixtures, respectively.

\subsubsection{Nitriding: bulk configuration - pretreated sample of pure $\mathrm{Fe}$}

The experimental system was also used to investigate the nitriding of $\alpha-\mathrm{Fe}$, but now instead of an untreated sample and surface configuration, a pretreated sample and bulk configuration were used. The conditions used are the same of the nitrocarburizing process. Once more, the nitrocarburizing in $\mathrm{N}_{2}-\mathrm{H}_{2}-\mathrm{CH}_{4}$ and the nitriding in $\mathrm{N}_{2}-\mathrm{H}_{2}$ mixtures presented similar results concerning the dependence of the ammonia profile on the hydrogen fraction in the gas mixture. Indeed, in both experiments, the results with pretreated samples of $\alpha$-Fe yielded the same trend, i.e., a broad distribution of $\mathrm{NH}_{3}$, indicating a relatively high intensity of ammonia formed in lower hydrogen concentrations, in addition to the stoichiometric one, around $30 \%$ and $75 \%$ respectively, as shown in Figure 9.

However, in the present case the bulk configuration was applied to the nitriding process, rather than the surface (as in nitrocarburizing). As noted in Section 3.1.1, the results found for the surface configuration when using a pretreated sample tend to approach those of the bulk configuration, displaying a broad distribution (Figures 2 and 4) where the two "types" of ammonia are present. Nevertheless, in the case of nitrocarburizing, more meticulous measurements were

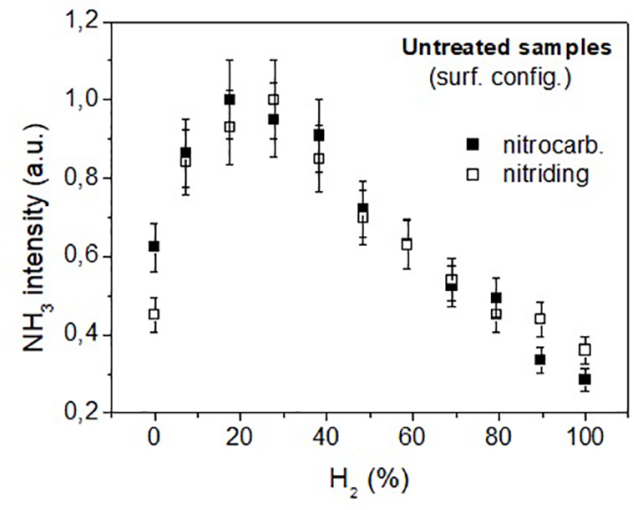

Figure 8. Evolution of the ammonia ion peak $\left(\mathrm{NH}_{3}^{+}\right)$obtained for the surface configuration using an untreated sample, during nitriding and nitrocarburizing process

made, and differences were then detected and investigated also using untreated samples.

Szabo and Wilhelmi ${ }^{5}$ also investigated the nitriding process in $\mathrm{N}_{2}-\mathrm{H}_{2}$ mixtures in a d.c. glow discharge, in $42 \mathrm{CrMo} 4$ steel, by mass spectrometry in similar conditions, although with a somewhat lower temperature $\left(500{ }^{\circ} \mathrm{C}\right)$ and higher pressure $(700 \mathrm{~Pa})$. As pointed out earlier ${ }^{6}$, their results tend to support our assumption. The experimental assembly of the cathodic region seems to be equivalent to that of our surface configuration. Their measurements in the cathode molecular beam were limited to $60 \% \mathrm{vol} \mathrm{H}_{2}$. Normalized to 1 (highest peak intensity), to facilitate comparison** of the profile shapes, it can be seen in Fig. 10 that in the common measured range and within the estimated uncertainty the curve of Szabo not only compares well with that of Egert ${ }^{6}$ (nitriding in $\mathrm{N}_{2}-\mathrm{H}_{2}$ dc glow), but also with Silva's results ${ }^{23}$ (nitrocarburizing 


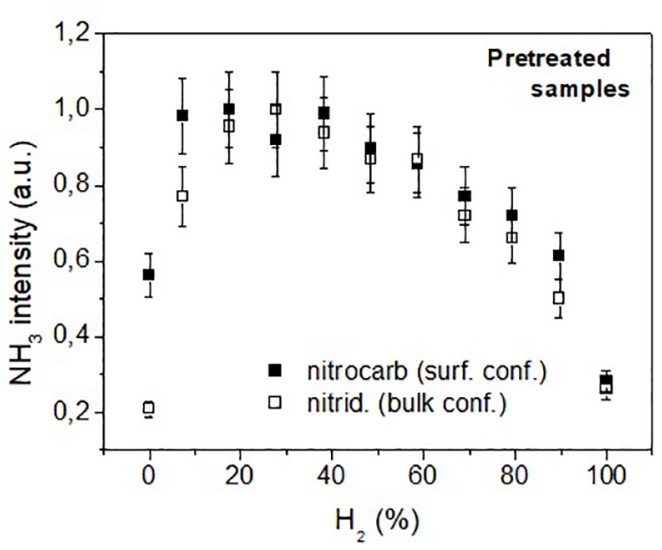

Figure 9. Evolution of the ammonia ion peak $\left(\mathrm{NH}_{3}^{+}\right)$obtained during nitriding (bulk configuration) and nitrocarburizing (surface configuration) process using a pretreated sample

in $\mathrm{N}_{2}-\mathrm{H}_{2}-\mathrm{CH}_{4}$ d.c. glow). Actually, Figure 10 corresponds to the plot of Szabo's data along with the data in Fig. 9 for the surface configuration of pretreated samples of Egert and Silva. The measurements of Szabo were performed during the nitriding treatment, which lasted for several hours. The treatment time of the cathode sample was not specified and, for our purpose, it was considered as a pretreated sample.

If we compare all the results for $\mathrm{NH}_{3}$ vs. $\mathrm{H}_{2}$ discussed in this work, for both configurations and all the sample conditions, we find that the first part of the curve, up to approximately $40 \% \mathrm{vol} \mathrm{H}_{2}$, is almost the same in all cases. This corresponds to the part containing the non-stoichiometric ammonia peak. The difference in the profiles appears only for $\mathrm{H}_{2}$ fraction values above $40 \%$, when the effects of the stoichiometric ammonia begins to be significant and then introduces differences between the curves.

The existence of a second $\mathrm{NH}_{3}$ peak, at lower hydrogen concentration, and which would be related to nitrogen consumption at the heated cathode surface during plasma nitriding or nitrocarburizing processes, was postulated by Egert et al. ${ }^{6}$ and later confirmed by Hansch et al. ${ }^{20}$ and by $\mathrm{Silva}^{23}$. As in the nitrocarburizing process, the removal of nitrogen from the surface, correlated to ammonia formation through a second reaction channel, would be responsible for the observed departure from the known observed stoichiometry for the ammonia formation. This is in agreement with Szabo and Wilhelmi ${ }^{5}$, who postulated the existence of another reaction channel involving nitrogen removal on the hot sample surface and ammonia formation supposedly correlated to the nitriding process. In their measurements, they observed ions with $\mathrm{m} / \mathrm{z}=72$ and $73 \mathrm{u}$ among the plasma species, which

\footnotetext{
** Although they used an analogous configuration (with a cathode plate pierced by a pinhole), the comparison between these curves must be considered with some caution, since in Egert's experiment $\mathrm{NH}_{3}$ molecules were collected and analyzed after ionization in the MS ionization chamber, whereas in the latter case they collected $\mathrm{NH}_{3}{ }^{+}$ions directly from the plasma. Therefore, we assume here that this will not invalidate a qualitative comparison
}

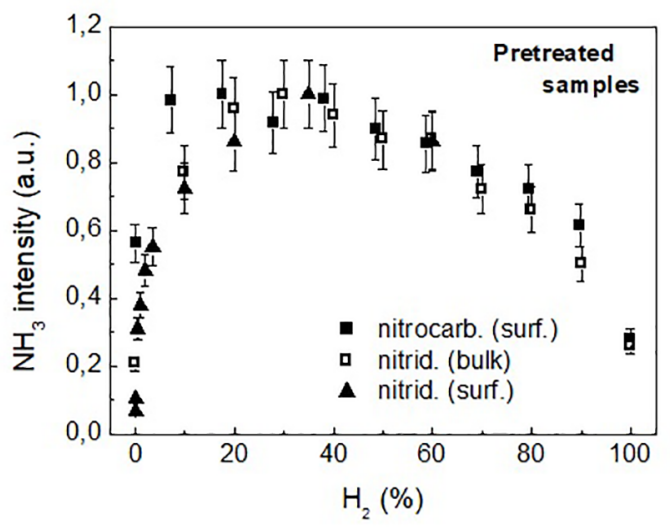

Figure 10. Comparison of the evolution of the ammonia ion peak $\left(\mathrm{NH}^{+}\right)$obtained during nitriding (bulk configuration) and nitrocarburizing (surface configuration) process with Szabo's results

they attributed to the nitrogen-containing species $\mathrm{FeNH}_{2-3}{ }^{+}$, and which would be intermediates in the formation of an unstable boundary layer of $\mathrm{Fe}_{2-4} \mathrm{~N}$ as well as of $\mathrm{NH}_{3}$ at the cathodic surface. These nitrides would be formed at the surface and ammonia would be released to the gas phase ${ }^{5}$ :

Egert ${ }^{22}$ also supposedly detected a mass peak from $\mathrm{FeNH}_{3}$ $\left(\mathrm{FeNH}_{3}{ }^{+}\right)$in nitriding experiments, but owing to difficulties encountered due to its feeble intensity measured in the MS, the author could not investigate this species.

\subsubsection{Comments on the diffusion layer thickness and ammonia formation}

In the previous short publication ${ }^{6}$ with preliminary results, we pointed out a possible correlation between the ammonia formation and the diffusion layer thickness in the nitriding process when using the bulk configuration/pretreated sample. The maximum diffusion layer thickness is found at $70 \% \mathrm{vol}$ $\mathrm{N}_{2}-30 \%$ vol $\mathrm{H}_{2}$, a value corresponding to the maximum obtained for $\mathrm{NH}_{3}$ density measured by mass spectrometry. The measurements were made on a pretreated sample with the bulk configuration. At the time, we had not yet considered the hypothesis of the non-stoichiometric ammonia. In view of the mixture condition specified above and of the present results, it appears that the diffusion layer thickness will also show a maximum coincidence with the $\mathrm{NH}_{3}$ profiles for nitriding and nitrocarburizing shown in Figure 8 for the surface configuration/untreated samples, and where the non-stoichiometric ammonia at $30 \% \mathrm{vol}_{2}$ is predominant. This supports our hypothesis, meaning that if the correlation mentioned above is to be considered valid it is very likely to be concerned with the non-stoichiometric ammonia.

We carefully reevaluated all the pertinent data originally obtained in the experiments. The results are shown in Figure 11a, where the scale of the diffusion layer thickness was adjusted for comparison of the profile maxima displayed in the figure. 
The diffusion layer thickness data were averaged over 5 measurements taken at distinct points of the sample surface. Figure $11 \mathrm{~b}$ shows the diffusion layer formed during the plasma nitriding process in a sample of sintered iron. Despite this, in a first approach, the distribution of these data points, particularly within the maximum portion of its corresponding profile, appears to display a trend similar to those of the $\mathrm{NH}_{3}$ intensities for nitriding and nitrocarburizing when using untreated samples. Therefore, it should be consistent with the idea of a correlation between the diffusion layer thickness and the non-stoichiometric ammonia formation.

\subsubsection{Temperature dependence of $\mathrm{NH}_{3}$}

In the nitriding experiment $\left(\mathrm{N}_{2}-\mathrm{H}_{2}\right.$ mixture $)$ also measured the dependence of the ammonia formation on the $\mathrm{H}_{2}$ fraction for three different temperatures in the steel cathode, namely 100, 250 and $540^{\circ} \mathrm{C}$ (Figure 12).

As noted in paragraph 3.2.1, surface configuration and untreated samples were used. Three distinct profiles were obtained. We clearly observed that as the temperature increased from 100 to $540^{\circ} \mathrm{C}$ the ammonia maximum gradually shifted to the left, to lower hydrogen fractions in the mixture. The relative intensity of ammonia peaks also increased with the temperature. It is worth comparing these curves with the results obtained from the experiments of nitrocarburizing for different configurations and samples (bulk/untreated, surface/untreated and surface/pretreated). Indeed, at $100^{\circ} \mathrm{C}$ the thermal effects of the cathode regarding surface treatment and the formation of non- stoichiometric ammonia are expected to be small or negligible. In this case, the preponderant source of ammonia is probably the heterogeneous catalysis through the reactor walls. One can see that the profile of this curve approaches that of Figure 2 for the bulk configuration with the untreated sample, also interpreted in the nitrocarburizing as being mainly resulting from the catalytic ammonia from the reactor walls.

At $250^{\circ} \mathrm{C}$, the thermal effects of the cathode are likely to become significant and ammonia would arise from two different mechanisms, reactor walls and heated cathode. The $250^{\circ} \mathrm{C}$ curve can be compared to that for the surface configuration with a pretreated sample (Fig. 4), which in our analysis represents this intermediary condition.

Finally, at $540^{\circ} \mathrm{C}$, the same temperature used for nitriding and nitrocarburizing in the surface configuration with untreated samples, the two curves (see Figure 3 and 12 at $540^{\circ} \mathrm{C}$ ) are very similar, indicating that the non-stoichiometric source of ammonia prevails. Once again, these curves showing the displacement of the ammonia maximum towards higher nitrogen consumption (lower hydrogen fraction) tend to support the supposition of a second mechanism to form ammonia. The temperature dependence of the ammonia intensity was also investigated for a given condition of the mixture, specifically $70 \%$ vol $\mathrm{N}_{2}-30 \%$ vol $\mathrm{H}_{2}$. The $\mathrm{NH}_{3}$ intensity increases consistently and, as expected, the results are in agreement with those of Fig. 12 for $30 \% \mathrm{vol} \mathrm{H}_{2}$. The temperature value found for the maximum ammonia intensity in this mixture is attained at around $400-450^{\circ} \mathrm{C}$ (Figure 13).

Actually, it could correspond either to the beginning of a broad maximum (seems most likely) or to the beginning of a plateau. The lack of points above $450^{\circ} \mathrm{C}$ makes it difficult to establish it. However, this maximum value is considerably higher than that measured by Botchway ${ }^{24}$ for the stoichiometric ammonia formed by heterogeneous catalysis when using Fe surface as catalyst in $\mathrm{N}_{2}-\mathrm{H}_{2}$ glow discharges in similar conditions of pressure, and which was found to be around $600 \mathrm{~K}\left(327^{\circ} \mathrm{C}\right)$. The curve profiles also are different in the two cases. We can thus reasonably assume that this ammonia arises from the non-stoichiometric source.

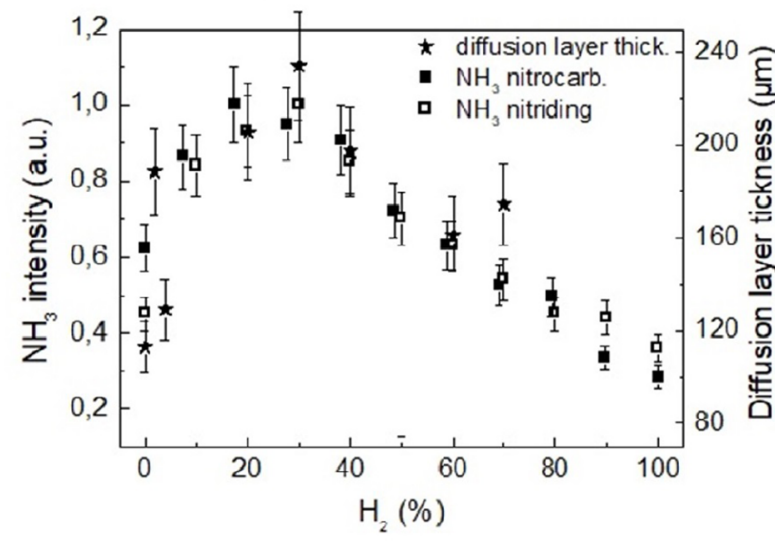

(a)

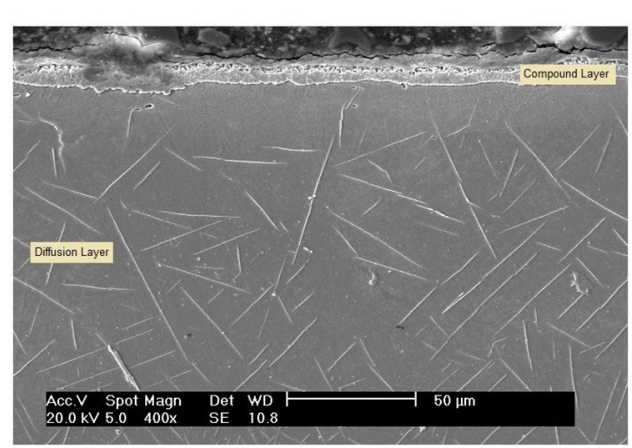

(b)

Figure 11. Correlation between the ammonia formation and the diffusion layer thickness obtained during nitriding and nitrocarburizing process 


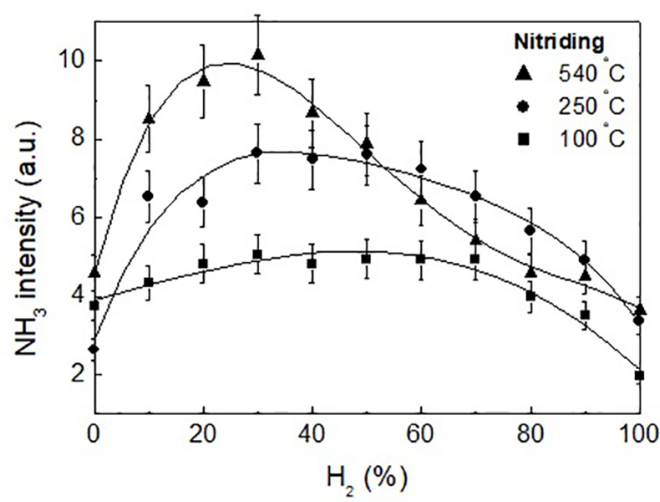

Figure 12. Evolution of the ammonia ion peak $\left(\mathrm{NH}_{3}^{+}\right)$obtained during nitriding for three different temperatures in the steel cathode: 100,250 and $540{ }^{\circ} \mathrm{C}$

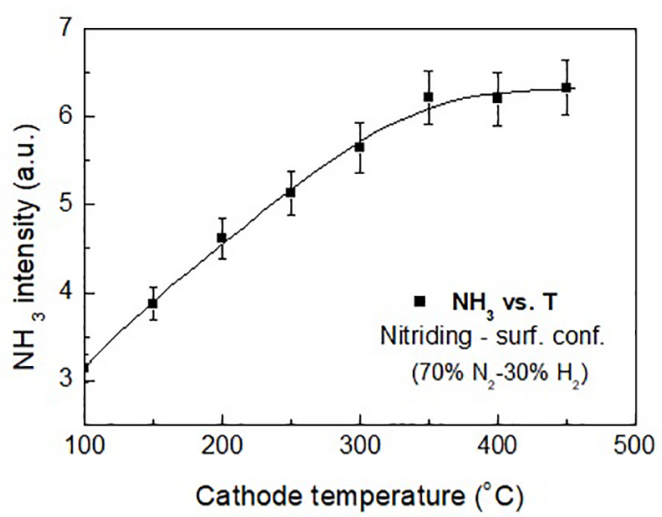

Figure 13. Evolution dependency of the ammonia ion peak $\left(\mathrm{NH}^{+}\right)$ with the temperature of the steel cathode, during nitriding

\section{Concluding Remarks}

This paper is devoted to the study of ammonia synthesis during the nitrocarburizing and nitriding processes in d.c. glow discharges sustained in different $\mathrm{N}_{2}-\mathrm{H}_{2}-\mathrm{CH}_{4}$ and $\mathrm{N}_{2}-$ $\mathrm{H}_{2}$ gas mixtures, respectively, chiefly by means of mass spectrometry. The experiments were conducted in two different configurations: one to collect and analyze species probed primarily in the bulk of the plasma, at a position distant from the heated cathodic sample, and the other to collect and analyze species probed very close to the reactive surface of the cathodic sample.

According to the literature, the $\mathrm{NH}_{3}$ synthesis in plasmachemical conversions containing $\mathrm{N}_{2}-\mathrm{H}_{2}$ mixtures results mainly from heterogenous reactions on the reactor walls, with an expected stoichiometry of $\mathrm{N}_{2}: \mathrm{H}_{2}=1: 3$. However, when using the surface configuration, we observed a departure from the expected stoichiometry of ammonia formation, with a well- defined shift towards higher nitrogen consumption, and resulting in a corresponding non-stoichiometric ratio $\mathrm{N}_{2}: \mathrm{H}_{2} \approx$ $3: 1$, in both plasma processes of this study. In this, the yield of the ammonia synthesis observed was largely dominant over the stoichiometric one. The unexpected removal of nitrogen with such a large deviation from the equilibrium stoichiometry appears to be correlated to the ammonia synthesis through a second reaction channel occurring on the heated sample surface. The temperature dependence plots also support the connection of the non-stoichiometric ammonia synthesis with the heated sample surface, as the departure from the equilibrium stoichiometry tends to increase with the temperature, eventually attaining the non-stoichiometric profile $\mathrm{N}_{2}: \mathrm{H}_{2} \approx 3: 1$ for $\mathrm{T} \approx 540^{\circ} \mathrm{C}$. On the other hand, unlike what was observed in the case of the untreated sample, when the sample surface is pretreated it tends to inhibit partially the synthesis of non-stoichiometric ammonia.

Another aspect observed is that the results concerning the diffusion layer thickness point to a possible correlation between the non-stoichiometric ammonia formation and the diffusion layer thickness in the nitriding process. The maximum diffusion layer thickness was found at $70 \%$ vol $\mathrm{N}_{2}-30 \%$ vol $\mathrm{H}_{2}$. This value corresponds to the maximum obtained for $\mathrm{NH}_{3}$ density measured by mass spectrometry. Concerning the temperature dependence of the ammonia synthesis, it can be observed that the temperature increased from 100 to $540^{\circ} \mathrm{C}$ and the ammonia maximum gradually shifted to lower hydrogen fractions in the mixture. The temperature dependence of the ammonia intensity was also investigated for a given condition of the mixture, specifically $70 \%$ vol $\mathrm{N}_{2}-30 \%$ vol $\mathrm{H}_{2}$. The $\mathrm{NH}_{3}$ intensity increased consistently and as expected, and the value found for the maximum ammonia intensity in this mixture was around $400-450^{\circ} \mathrm{C}$.

The results obtained also indicate that nitrocarburizing and nitriding processes have similar behavior concerning the non-stoichiometric ammonia formation.

These results are consistent with those of Szabo and Wilhelmi ${ }^{5}$, who postulated the existence of another reaction channel involving nitrogen removal at the hot sample surface and ammonia formation supposedly correlated to the nitriding process.

We have described the experimental results obtained from empirical observations of the plasma treatment processes to arrive at the correlations that have been presented.

More detailed research concerning the morphological and microchemical is required to understand the physical chemistry involved.

\section{Acknowledgements}

This paper is dedicated to the memory of Professor Joël L. R. Muzart, dearly missed by his friends and colleagues. He often made valuable comments and suggestions during the experimental work period. We would like to express our thanks to Dr. Argemiro S. da Silva Sobrinho for helpful discussions concerning the nitrocarburizing 
results. The authors P. Egert and A. Seeber were supported by graduate grants from the CAPES (Coordination for the Improvement of Higher Education Personnel), and H.R.T. Silva by a graduate grant from the $\mathrm{CNPq}$ (National Council for Scientific and Technologicla Development). This work was partially supported by the Capes/Cofecub (Comite Français d'Evaluation de la Coopération Universitaire avec le Brésil) no. 233/98; and partially by Pronex (Programa de Apoio a Núcleos de Excelência)-CNPq, Brazil. We would like to express our thanks to the CAPES and CNPq for the financial support and grants.

\section{REFERENCES}

1. Sun Y, Bell T. A numerical model of plasma nitriding of low alloy steels. Materials Science and Engineering: A. 1997;224(1-2):3347.

2. Edenhofer B, Gräfen W, Müller-Ziller J. Plasma-carburising - a surface heat treatment process for the new century. Surface and Coatings Technology. 2001;142-144:225-234.

3. Chen FS, Chang CN. Effect of CH4 addition on plasma nitrocarburizing of austenitic stainless steel. Surface and Coatings Technology. 2003;173(1):9-18.

4. Li S, Manory RR. Comparison of compound layer nucleation mechanisms in plasma nitriding and nitrocarburizing: the effect of CHn species. Journal of Materials Science. 1999;34(5):10451049.

5. Szabo A, Wilhelmi H. Mass spectrometric diagnosis of the nitriding mechanism in a d.c. glow discharge surface. Plasma Chemistry and Plasma Process. 1984;4(2):89-105.

6.. Egert P, Speller CV, Amorim J, Maliska AM. Mass spectrometric study of ammonia during the plasma nitriding process by a glow discharge. In: Proceedings of the 14th International Symposium on Plasma Chemistry; 1999 Aug 2-6; Prague, Czech Republic.

7. Quandt M, Egert P, Silva HRT, Speller CV. Investigation of ammonia formation and its involvement in the nitriding process. In: Proceedings of the 6th Asia Pacific Conference On Plasma Science And Technology (6th APCPST); 2002 Jul 1-4; Cheju, South Korea.

8. Seeber A. Desenvolvimento de um sistema experimental para o estudo da interação plasma-superficie utilizando a técnica de espectrometria de massa. [Dissertation] Florianópolis: Universidade Federal de Santa Catarina; 1997.

9. P.J. Linstrom and W.G. Mallard, Eds., NIST Chemistry WebBook, NIST Standard Reference Database Number 69, National Institute of Standards and Technology, Gaithersburg MD, 20899, doi:10.18434/ T4D303, Accessed 6 March 2017.

10. Touimi S, Jauberteau JL, Jauberteau I, Aubreton J. Plasma chemistry and diagnostic in Ar-N2-H2 microwave expanding plasma used for nitriding experiments. Journal of Physics D: Applied Physics. 2010;43(20):205203.
11. Ricard A, Gordiets BF, Pinheiro MF, Ferreira CM, Baravian G, Amorim J, et al. Diagnostic and modeling of N2-H2 discharges for iron nitriding. The European Physical Journal - Applied Physics. 1998;4(1):87-93.

12. Pintassilgo CD, Loureiro J, Cernogora G, Touzeau M. Methane decomposition and active nitrogen in a N2-CH4 glow discharge at low pressures. Plasma Sources Science and Technology. 1999;8(3):463478.

13. Hong J, Prawer S, Murphy AB. Plasma catalysis as an alternative route for ammonia production: status, mechanisms, and prospects for progress. Sustainable Chemistry \& Engineering. 2018;6(1):15-31.

14. Touvelle M, Muñoz Licea JL, Venugopalan M. Plasma chemical synthesis. II. Effect of wall surface on the synthesis of ammonia. Plasma Chemistry and Plasma Processing. 1987;7(1):101-108.

15. Eremin EN, Mal'tsevAN, Syaduk VL. Catalytic synthesis of ammonia in a barrier discharge. Russian Journal of Physical Chemistry. 1971;45(5):635-638.

16. Gordiets B, Ferreira CM, Pinheiro MJ, Ricard A. Self-consistent kinetic model of low-pressure N2-H2 flowing discharges: II. Surface processes and densities of N, H, NH3 species. Plasma Sources Science and Technology. 1998;7:379-388.

17. Amorim J, Baravian G, Sultan G. Absolute density measurements of ammonia synthesized in N2-H2 mixture discharges. Applied Physics Letters. 1996;68(14):1915-1917.

18. Uyama $\mathrm{H}$, Matsumoto O. Synthesis of ammonia in high-frequency discharges. II. Synthesis of ammonia in a microwave discharge under various conditions. Plasma Chemistry and Plasma Process. 1989;9(3):421-431.

19. Bai MD, Bai XY, Zhang ZT, Bai M. Synthesis of Ammonia in a Strong Electric Field Discharge at Ambient Pressure. Plasma Chemistry and Plasma Process. 2000;20(4):512-520.

20. Quandt M. Formação de amônia durante o processo de nitretação por plasma. [Dissertation]. Florianópolis: Universidade Federal de Santa Catarina; 2002. Available from: $<$ http://www.tede.ufsc.br/ teses/PCEM0062.pdf $>$. (in Portuguese). Access in: 30/03/2017.

21. Bai MD, Zhang ZT, Bai XY, Gao H. Synthesis of Ammonia Using CH4/N2 Plasmas Based on Micro-Gap Discharge under Environmentally Friendly Condition. Plasma Chemistry and Plasma Process. 2008;28(4):405-414.

22. Ortiz PE. Estudo da nitretação por plasma: correlação plasmasuperficie. [Thesis]. Florianópolis: Universidade Federal de Santa Catarina; 2000. 148 f. Available from: https://repositorio.ufsc.br/ handle/123456789/79253 (in Portuguese). Access in: 16/03/2017.

23. Silva HRT. Estudo do processo de nitrocementação por plasma. [Thesis]. Florianópolis: Universidade Federal de Santa Catarina; 2003. Available from: \&lt;http://www.tede.ufsc.br/teses/PCEM0069. pdf\&gt;. (in Portuguese). Access in: 16/03/2017.

24. Botchway GY, Venugopalan M. Plasma Synthesis of Ammonia in Presence of an Iron Catalyst. Zeitschrift für Physikalische Chemie. 1980;120:S103-S110. 